\title{
Acute and Long-Term Effects of Gastrin on Muscle and Bone Calcium Uptake in Rats
}

\author{
Nateetip KRishnamRa and Liangchai LimLOMwONGSE \\ Department of Physiology, Faculty of Science, Mahidol University, \\ Rama VI Road, Bangkok 10400, Thailand
}

(Received July 24, 1995)

\begin{abstract}
Summary It has previously been proposed that the hypocalcemic action of gastrin was mediated by a gastric peptide gastrocalcin which enhanced bone uptake of calcium ( $\mathrm{Ca}$ ). The present study, thus, aimed to reconfirm the effect of gastrin on muscle and bone $\mathrm{Ca}$ uptake and to evaluate a possible direct effect of gastrin on tissue Ca uptake. First, we showed that human and rat gastrin $(100 \mu \mathrm{g} / 100 \mathrm{~g}$ body weight (bw), s.c.) acutely increased uptake of intragastrically administered ${ }^{45} \mathrm{Ca}$ by the tibia and femur. Interestingly, human gastrin was more effective and also enhanced ${ }^{45} \mathrm{Ca}$ uptake by the gastrocnemius muscle. In order to find out whether gastrin could act directly on bone, $10 \mu \mathrm{g}$ of rat gastrin $/ 100 \mathrm{~g}$ bw and ${ }^{45} \mathrm{Ca}$ were injected into the right femoral artery supplying the right leg while the left leg received normal saline and an equal amount of ${ }^{45} \mathrm{Ca}$. At $30 \mathrm{~min}$, the right gastrocnemius muscle and femur were found to contain $168 \%$ and $162 \%$, respectively, more ${ }^{45} \mathrm{Ca}$ than the left leg. In contrast, daily administration of $25 \mu \mathrm{g}$ of rat gastrin $/ 100 \mathrm{~g} \mathrm{bw}$, s.c., for 2 weeks had no effect on muscle or bone total $\mathrm{Ca}$ content while the content of ${ }^{45} \mathrm{Ca}$ given on days 12 and 13 was lower in the tibia and femur of gastrintreated rats. It could be concluded that gastrin transiently enhanced $\mathrm{Ca}$ uptake by muscle and bone. However, two-week treatment with gastrin appeared to accelerate the bone turnover rate i.e., enhanced uptake and release of calcium, so that there were no net changes in bone total $\mathrm{Ca}$ content at the end of the experimental period.
\end{abstract}

Key Words bone calcium uptake, bone turnover, calcium, calcium homeostasis, gastrin, hypocalcaemia, muscle calcium uptake

The plasma calcium concentration is normally regulated by three main calcium-regulating hormones, parathyroid hormone, $1,25(\mathrm{OH})_{2} \mathrm{D}_{3}$ and calcitonin. However, as increasing body of evidence suggests that other hormones may also play a role in the regulation of calcium homeostasis. Gastrin has been shown to induce hypocalcaemia in intact and thyroparathyroidectomized rats $(1-4)$ and in chicks (5). This suggested that the effect was not mediated by the release of 
calcitonin or suppression of parathyroid hormone secretion.

Recently, the hypocalcaemic effect of gastrin has been reported to be mediated by a hypocalcaemic gastrin peptide referred to as gastrocalcin which is thought to act by enhancing the transfer of calcium from blood to bone (6). Whichever is the hypocalcaemic agent, the stomach evidently plays an essential role in the maintenance of calcium homeostasis.

There seems to be controversy regarding the importance of the stomach in the hypocalcaemic action of gastrin. There were reports that gastrin-induced hypocalcaemia was abolished by gastrectomy or removal of the acid-producing fundus ( 1 , 2,6,7). Moreover, gastrectomy abolished the enhanced uptake of ${ }^{45} \mathrm{Ca}$ into bone seen after gastrin administration (8). On the other hand, we had previously demonstrated that acute hypocalcaemia induced by an intraperitoneal injection of $50 \mu \mathrm{g}$ porcine gastrin was observed in gastrectomized rats within $30 \mathrm{~min}$ after hormone administration (9). Thus, there was a possibility that gastrin could exert a hypocalcaemic action directly on bone, independently of the proposed gastric peptide.

Therefore, the present investigation aimed to evaluate the direct action of gastrin on bone uptake of calcium after both acute and long-term administration of gastrin.

\section{MATERIALS AND METHODS}

Materials. Human gastrin-17 and rat gastrin-17 were purchased from Sigma, St. Louis, MO, USA. ${ }^{45} \mathrm{Ca}$, initial specific activity $2 \mathrm{mCi} / \mathrm{ml}(1 \mathrm{Ci}=37 \mathrm{GBq})$ was obtained from Radiochemical Centre, Amersham, UK.

Animals. Sexually mature male Wistar rats, weighing about $200 \mathrm{~g}$ were obtained from the Animal Centre of Thailand, Salaya Campus, Mahidol University. The animals were kept in hanging stainless steel cages under a $12 \mathrm{~h}$ light: $12 \mathrm{~h}$ dark cycle and maintained on laboratory rat chow containing $1.5 \% \mathrm{Ca}, 1.0 \% \mathrm{P}$ and 2,500 IU/kg vitamin D (C.P. Co. Ltd, Thailand) and tap water ad libitum.

\section{Experimental procedures.}

Part I. Reevaluation of the acute effect of human and rat gastrin on muscle and bone calcium uptake

After an overnight fast, the animals were anaesthetized with an intraperitoneal injection of sodium pentobarbital (Nembutal, $60 \mathrm{mg} / \mathrm{kg}$ ) and tracheostomized. Body temperature was maintained at $37^{\circ} \mathrm{C}$ by an overhead heating lamp connected to the temperature regulator (YSI model 73A, Yellow Spring Instruments, Yellow Springs, OH, USA). The femoral artery and vein were catheterized with a No. 50 polyethylene tube filled with heparinized saline (50 IU heparin/ml) and normal saline, respectively. After the animal preparation, with the use of a stomach tube, $1 \mathrm{ml}$ of $5 \mathrm{mM} \mathrm{CaCl}_{2}$ containing $5 \mu \mathrm{Ci}^{45} \mathrm{CaCl}_{2}$ was instilled into the stomach. Fifteen minutes later, either normal saline or $100 \mu \mathrm{g}$ human or rat gastrin/100 g bw were injected subcutaneously; this was regarded as time zero minute. At $30 \mathrm{~min}$, the 
gastrocnemius muscle, tibia and femur were removed for determination of total calcium and ${ }^{45} \mathrm{Ca}$ contents.

Part II. Evaluation of possible direct effect of gastrin on femoral uptake of ${ }^{45} \mathrm{Ca}$

a. Control experiment to show distribution of ${ }^{45} \mathrm{Ca}$ injected into the right femoral artery. After tracheostomy, the proximal end of the right femoral artery was catheterized with PE 50 but with the catheter tip in the direction of the leg for delivery of ${ }^{45} \mathrm{Ca}$ into the right leg. At time zero minute, $0.3 \mathrm{ml}$ of $1 \mathrm{mM} \mathrm{CaCl}_{2}$ containing $5 \mu \mathrm{Ci}^{45} \mathrm{CaCl}_{2}$ was administered as a single dose into the right leg via the right femoral artery. Thirty minutes later, both the left and right gastrocnemius muscles and femurs were removed.

b. Evaluation of the direct effect of rat gastrin on bone ${ }^{45} \mathrm{Ca}$ uptake. In this study, both left and right femoral arteries were catheterized with the catheter tip pointing in the direction of the leg. At time zero minute, $0.3 \mathrm{ml}$ of $1 \mathrm{mM} \mathrm{CaCl}_{2}$ containing $5 \mu \mathrm{Ci}^{45} \mathrm{CaCl}_{2}$ was administered into the respective left and right femoral arteries, but $5 \mathrm{~min}$ prior to ${ }^{45} \mathrm{Ca}$ administration, $10 \mu \mathrm{g}$ rat gastrin $/ 100 \mathrm{~g}$ bw was delivered via the right femoral catheter while normal saline of the same volume was delivered via the left femoral catheter. Thus, the left leg served as the control while the right leg received a full dose of gastrin. At $30 \mathrm{~min}$, both the left and right gastrocnemius muscles and femurs were removed.

Part III. Effect of prolonged administration of gastrin over 14 days on calcium and ${ }^{45} \mathrm{Ca}$ contents in gastrocnemius muscle and femur

Male Wistar rats weighing about $150 \mathrm{~g}$ were divided randomly into 2 groups, one group receiving a daily subcutaneous injection of normal saline and the other receiving a daily subcutaneous injection of $25 \mu \mathrm{g}$ rat gastrin $/ 100 \mathrm{~g}$ bw. Body weight and food intake were recorded daily over the entire experimental period of 14 days. In the morning of days 12 and 13, all animals received a subcutaneous administration of $1 \mathrm{mM} \mathrm{CaCl} 2$ containing $5 \mu \mathrm{Ci}{ }^{45} \mathrm{CaCl}_{2}$. On day 14 , the animals were sacrificed and the gastrocnemius muscle and femur were removed.

Analyses. The gastrocnemius muscle was rinsed with normal saline, blotted dry and weighed before being dried at $80^{\circ} \mathrm{C}$ in the oven for $24 \mathrm{~h}$. Dry muscle weight was recorded and the muscle was ashed for $16 \mathrm{~h}$ in the muffle furnace at $600^{\circ} \mathrm{C}$.

Bones were cleaned of adhering tissues, rinsed in normal saline, blotted dry and cut in half. The bone cavity was flushed with normal saline ejected from a syringe. After blotting dry and weighing, bone was dried in the oven at $80^{\circ} \mathrm{C}$ for $24 \mathrm{~h}$. Dry bone weight was recorded and bone was ashed in the muffle furnace at $80^{\circ} \mathrm{C}$ for $16 \mathrm{~h}$. The muscle and bone ashes were later dissolved in $3 \mathrm{M} \mathrm{HCl}$ and the total calcium and ${ }^{45} \mathrm{Ca}$ concentrations were determined by atomic absorption spectrophotometry (Varian AA575) and liquid scintillation counter (LKB model 1219), respectively. Total calcium content is expressed as $\mathrm{mmol} / \mathrm{g}$ dry weight and ${ }^{45} \mathrm{Ca}$ content was expressed as \% administered dose/g dry weight.

Statistical analyses. All data are presented as $\mathbf{M} \pm$ SEM. Student's $t$-test was used to compare two sets of data. $p<0.05$ was considered significant.

Vol. 41, No. 6, 1995 


\section{RESULTS}

The acute effect of human and rat gastrin on muscle and bone ${ }^{45} \mathrm{Ca}$ uptake

Both human and rat gastrin subcutaneously administered at the dose of $100 \mu \mathrm{g} /$ $100 \mathrm{~g}$ bw resulted in a significant increase in ${ }^{45} \mathrm{Ca}$ uptake by the tibia and femur, as shown in Fig. 1. On the other hand, human gastrin, but not rat gastrin, had an effect on muscle accumulation of ${ }^{45} \mathrm{Ca}$. It was interesting to see that human gastrin was more effective in enhancing the ${ }^{45} \mathrm{Ca}$ uptake by bone.

\section{Evaluation of possible direct effect of gastrin on femoral uptake ${ }^{45} \mathrm{Ca}$}

Figure 2 depicts the total ${ }^{45} \mathrm{Ca}$ contents in the left and right gastrocnemius muscles and femurs when ${ }^{45} \mathrm{Ca}$ was delivered by the femoral arterial catheter into the right leg. At $30 \mathrm{~min}$ after ${ }^{45} \mathrm{Ca}$ administration, both gastrocnemius muscles contained a similar amount of ${ }^{45} \mathrm{Ca} \quad(7.09 \pm 1.86$ vs. $6.60 \pm 1.31 \%$ administered dose/g dry weight in left and right muscle, respectively) while the right femur contained significantly higher ${ }^{45} \mathrm{Ca}$ content than the left femur $(7.27 \pm 0.37$ vs. $4.18 \pm 0.66 \%$ administered dose $/ g$ dry weight, $p<0.01)$.

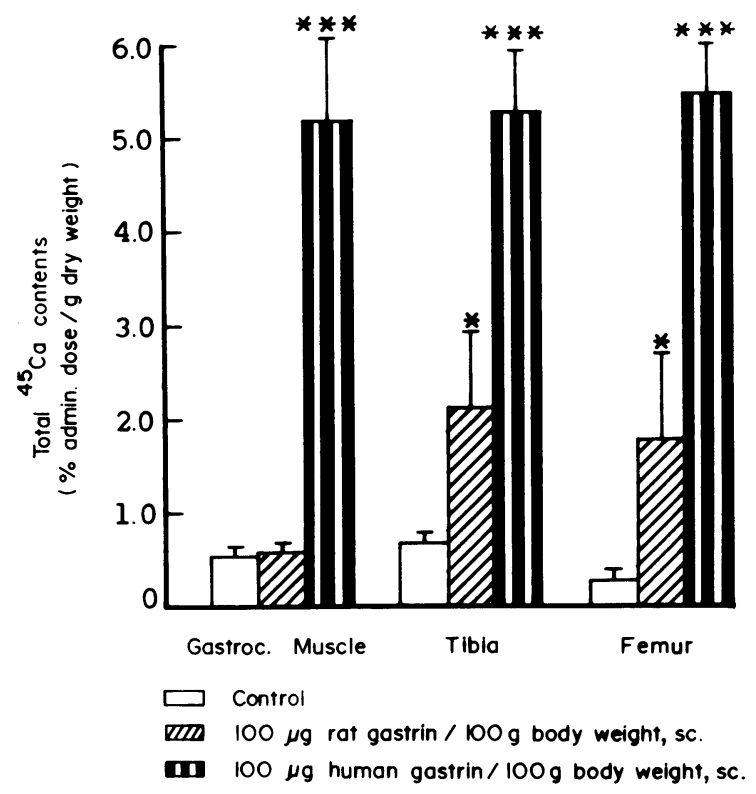

Fig. 1. The ${ }^{45} \mathrm{Ca}$ uptake ( $\%$ administered dose/g dry weight) by gastrocnemius muscle, tibia and femur of rats which were given intragastric administration of 5 $\mathrm{mM} \mathrm{CaCl} 2$ containing $5 \mu \mathrm{Ci}^{45} \mathrm{Ca} 15 \mathrm{~min}$ before subcutaneous injection of normal saline (control) or human or rat gastrin at a dose of $100 \mu \mathrm{g} / 100 \mathrm{~g}$ body weight. ${ }^{*} p<0.05,{ }^{* * *} p<0.001$ compared with control. 


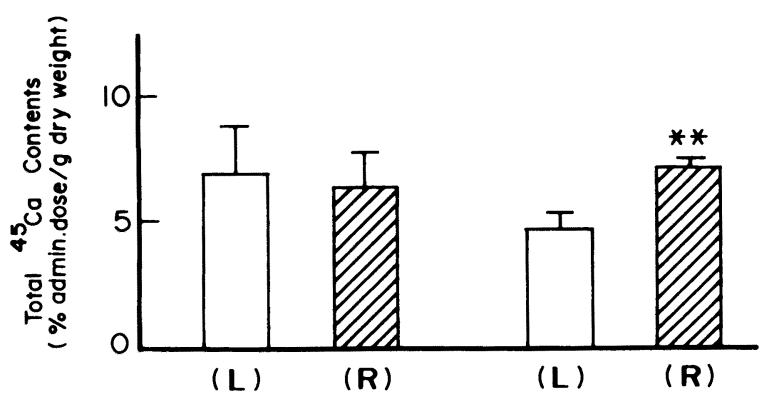

Fig. 2. The ${ }^{45} \mathrm{Ca}$ contents (\% administered dose/g dry weight) in left (L) and right (R) gastrocnemius muscle and femurs in rats which received an intraarterial injection of $1 \mathrm{mM} \mathrm{CaCl} 2$ containing $5 \mu \mathrm{Ci}^{45} \mathrm{CaCl}_{2}$ into the femoral artery supplying the right leg. ${ }^{* *} p<0.01$ compared with the left femur.

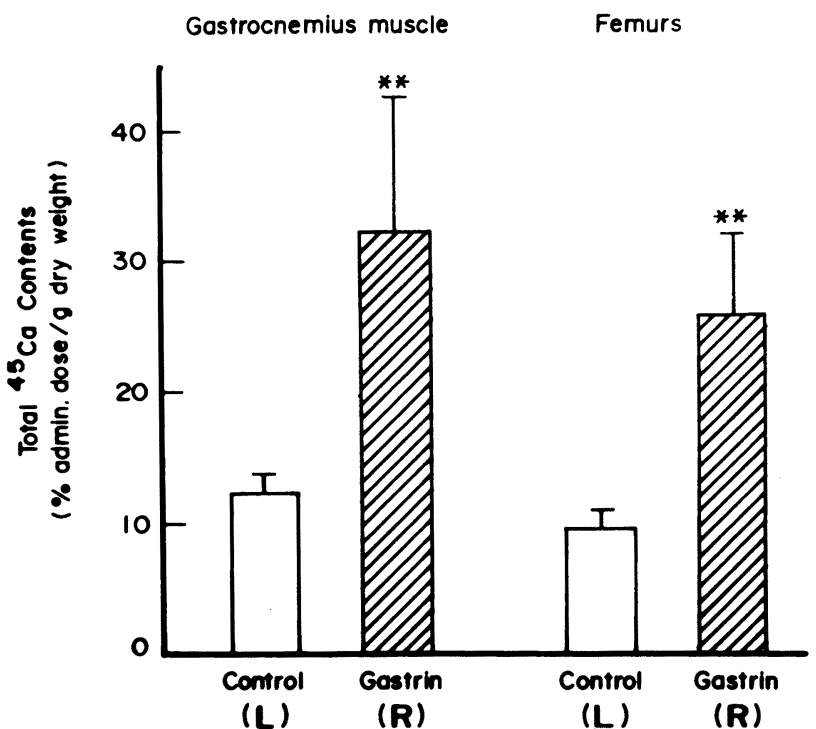

Fig. 3. The ${ }^{45} \mathrm{Ca}$ contents (\% administered dose/g dry weight) in the left (L) and right $(R)$ gastrocnemius muscle and femurs in rats which received an intraarterial injection of normal saline into the left femoral artery and $10 \mu \mathrm{g}$ rat gastrin/ $100 \mathrm{~g}$ body weight into the right femoral artery $5 \mathrm{~min}$ before the intraarterial administration of $1 \mathrm{mM} \mathrm{CaCl} 2$ containing $5 \mu \mathrm{Ci}^{45} \mathrm{CaCl}_{2}$ into both femoral arteries. ${ }^{* *} p<0.01$ compared with the control left. 
Table 1. The water content (\% wet weight) and the wet weight in relation to body weight of the gastrocnemius muscle and femurs of rats. The left and right legs received intrafemoral injection of $\mathrm{NaCl}$ and $10 \mu \mathrm{g}$ of gastrin/100 $\mathrm{g}$ body weight respectively, 35 min prior to the removal of tissues.

\begin{tabular}{ccc}
\hline & Water content $(\%$ wet weight) & Wet weight $(\%$ body weight $)$ \\
\hline Gastrocnemius muscle & & \\
Control $(n=10)$ & $75.5 \pm 0.67$ & $0.53 \pm 0.01$ \\
Gastrin $(n=10)$ & $75.5 \pm 0.69$ & $0.56 \pm 0.006$ \\
Femur & & \\
Control $(n=10)$ & $48.4 \pm 1.90$ & $0.32 \pm 0.009$ \\
Gastrin $(n=10)$ & $47.4 \pm 1.98$ & $0.32 \pm 0.008$ \\
\hline
\end{tabular}

Table 2. Effects of daily subcutaneous administration of $25 \mu \mathrm{g}$ of rat gastrin $/ 100 \mathrm{~g}$ body weight for 2 weeks on calcium contents ( $\mathrm{mmol} / \mathrm{g}$ dry weight) and ${ }^{45} \mathrm{Ca}$ contents ( $\%$ administered dose/g dry weight) in gastrocnemius muscle, tibia and femur of intact rats.

\begin{tabular}{lcc}
\hline & $\begin{array}{c}\text { Control } \\
(n=8)\end{array}$ & $\begin{array}{c}\text { Rat gastrin } \\
(n=8)\end{array}$ \\
\hline Calcium contents (mmol/g dry weight) & & \\
$\quad$ Gastrocnemius muscle & $0.31 \pm 0.13$ & $0.35 \pm 0.12$ \\
Tibia & $5.78 \pm 0.57$ & $5.21 \pm 0.50$ \\
Femur & $5.31 \pm 0.40$ & $5.16 \pm 0.42$ \\
${ }^{45}$ Ca contents (\% admin/g dry weight) & & \\
Gastrocnemius muscle & $0.04 \pm 0.01$ & $0.03 \pm 0.001$ \\
Tibia & $1.80 \pm 0.23$ & $1.49 \pm 0.18^{*}$ \\
Femur & $2.33 \pm 0.35$ & $1.59 \pm 0.16^{*}$ \\
\hline
\end{tabular}

$*_{p}<0.05$ compared with control.

It could be seen from Fig. 3 that for the right leg which received gastrin, the gastrocnemius muscle contained $32.33 \pm 10.89 \%$ administered dose ${ }^{45} \mathrm{Ca} / \mathrm{g}$ dry weight which was significantly higher than that in the muscle of the control left leg $(12.34 \pm 1.24 \%$ administered dose/g dry weight, $p<0.001)$. Similarly, the ${ }^{45} \mathrm{Ca}$ content in the right femur $(20.62 \pm 6.18 \%$ administered dose/g dry weight) was significantly higher than that in the left femur $(9.49 \pm 2.63 \%$ administered dose $/ \mathrm{g}$ dry weight).

Table 1 shows the water content (\% wet weight calculated from the difference between wet and dry weight of tissue) and wet weight (as \% of bw) of muscle and bone of the control left leg and gastrin-treated right leg. There was no difference between the control and gastrin-treated legs.

Effect of prolonged administration of gastrin over 14 days on calcium and ${ }^{45} \mathrm{Ca}$ contents in gastrocnemius muscle and femur

As shown in Table 2, daily subcutaneous injection of $25 \mu \mathrm{g}$ of rat gastrin/100 
$\mathrm{g}$ bw for 14 days did not have any effect on the total calcium contents either in the gastrocnemius muscle or bone. As for the ${ }^{45} \mathrm{Ca}$ which was administered on days 12 and 13 , gastrin-treated rats had significantly less ${ }^{45} \mathrm{Ca}$ in tibia $(1.49 \pm 0.18$ vs. $1.80 \pm$ $0.23 \%$ administered dose/g dry weight, $p<0.05)$ and femur $(1.59 \pm 0.16$ vs. $2.33 \pm$ $0.35 \%$ administered dose $/ \mathrm{g}$ dry weight, $p<0.05$ ) compared to the control.

\section{DISCUSSION}

Recent evidence has strengthened the hypothesis that the stomach is important for calcium homeostasis. The stomach is important not only for secreting acid which enhances intestinal calcium absorption (10-12) but gastrin from the antrum has been shown to lower the plasma level of calcium $(1-4,13)$ and may be responsible for immobilization-induced hypocalcaemia in rats (14). The fact that gastrectomy reduces bone weight, bone density $(15)$, bone mineral content $(16,17)$ and may result in metabolic bone disease (18-21) suggests that gastrin could be involved in bone metabolism. Furthermore, although gastric antrectomy brought about a decrease in bone weight and ash calcium content (22), there were also controversies concerning the presence of stomach and bone metabolism. Both normal (19) and increased $(22,23)$ bone turnover have been described in gastrectomy patients.

The present study confirmed earlier findings that gastrin acutely elevated calcium uptake by bone (8). It was surprising to find that human gastrin at the same dose was more potent than rat gastrin when tested in the rat. Besides, human gastrin was found to increase ${ }^{45} \mathrm{Ca}$ uptake by the gastrocnemius muscle as well as bone. The exact reason for this is unknown.

Since it has been hypothesized that the acute effect of gastrin on bone was mediated by the release of gastrocalcin from the fundus (6), we designed an experiment to test this by delivering gastrin directly into one leg of the animal while leaving the other leg as a control. ${ }^{45} \mathrm{Ca}$ of the same amount was also delivered directly into both femoral arteries supplying the left and right femurs and gastrocnemius muscles.

Before testing the effect of gastrin, it was interesting to see how ${ }^{45} \mathrm{Ca}$ was distributed if it was administered as described but only to one leg. After $30 \mathrm{~min}$, there seemed to be an even distribution of ${ }^{45} \mathrm{Ca}$ between the left and right gastrocnemius muscles (Fig. 2). On the other hand, there was $42 \%$ more ${ }^{45} \mathrm{Ca}$ present in the right femur which received direct ${ }^{45} \mathrm{Ca}$ injection. Thus, even in the absence of exogenous hormone, the right femur, when exposed to a high ${ }^{45} \mathrm{Ca}$ concentration, could extract and retain more ${ }^{45} \mathrm{Ca}$ than the muscle. This is probably due to the physicochemical nature of calcium movements into and out of quiescent bone surfaces which normally contributes to homeostatic control of the plasma calcium concentration (24).

As seen in Fig. 3, within 30 min, the right leg which received gastrin had 168\% and $162 \%$ more ${ }^{45} \mathrm{Ca}$ in the femur and gastrocnemius muscle, respectively, than in 
the left leg. As an equal amount of ${ }^{45} \mathrm{Ca}$ was delivered directly into both legs, the higher ${ }^{45} \mathrm{Ca}$ contents in the right leg was not due to different amounts of ${ }^{45} \mathrm{Ca}$ available, nor was it due to more blood being retained in the tissue, since the tissue wet weight was not different from the control left leg (Table 1).

Although we did not perform gastrectomy or fundectomy to remove the source of gastrocalcin, it probably played a minor role under the present conditions. If gastrin action on tissue calcium uptake was mediated by gastrocalcin, this gastric peptide once released, should reach both legs by circulation immediately and equally. In that case, one would expect gastrocalcin to exert an equal effect on both femurs which should consequently result in a similar degree of enhanced ${ }^{45} \mathrm{Ca}$ uptake. The present results, on the other hand, showed marked increase in ${ }^{45} \mathrm{Ca}$ uptake by muscle and femur of the gastrin-treated leg which could only be attributed to the administered gastrin.

It was noted that muscle uptake of ${ }^{45} \mathrm{Ca}$ was significantly increased by gastrin when administered intrafemorally (Fig. 3), in contrast to no effect when administered intraperitoneally (Fig. 1). To explain this discrepancy, we considered how the different routes of administration affected the concentration of gastrin at the target tissue. Since gastrin is not preferentially metabolized by the liver but is removed across capillary beds in tissue throughout the body, the amount delivered to the gastrocnemius muscle after an intraperitoneal injection must be substantially reduced. On the other hand, despite a smaller dose of gastrin intrafemorally administered, this direct delivery of gastrin bolus into the blood supply to the leg should result in a high concentration of gastrin in the gastrocnemius muscle. The present results suggested that muscle had lower responsiveness to gastrin as compared to bone and would respond to a high dose of gastrin. Since we did not perform a dose response study of gastrin effect on the muscle uptake of calcium, we could not exclude the possibility that the observed increase in ${ }^{45} \mathrm{Ca}$ uptake by the gastrocnemius muscle was a nonspecific response to a high concentration of gastrin. This explanation also applied to the long-term experiment in which a lower dose of gastrin was administered by the subcutaneous route. The absence of a change in muscle calcium content was likely to be due to a low concentration of gastrin.

Prolonged treatment of gastrin over 2 weeks had no effect on food intake or weight gain. The calcium contents of muscle, tibia and femur of gastrin-treated rats were not different from those of control. This finding is in accordance with a report that omeprazole-evoked hypergastrinaemia for 4 weeks did not raise the bone ash weight (8). Apparently, there was a discrepancy in bone ${ }^{45} \mathrm{Ca}$ content data between the acute and long-term experiments. In the long-term study, ${ }^{45} \mathrm{Ca}$ was administered on days 12 and 13 and bone ${ }^{45} \mathrm{Ca}$ content was evaluated on the 14th day. Normally, bone mass is determined by bone turnover which involves a wellregulated coupling of the processes of bone formation and resorption. In adults, bone turnover does not result in bone growth but helps to maintain bone integrity by the process known as bone remodeling which involves the activities of osteoblasts and osteoclasts. However, $80 \%$ of bone surfaces at any time are covered with 
lining osteoblasts which are not actively taking part in bone remodeling (25). It is this large quiescent suface area across which movement of calcium occurs that plays a role in the instantaneous moment-to-moment regulation of plasma calcium $(25,26)$. The ${ }^{45} \mathrm{Ca}$ content in bone on day 14 probably reflected the turnover of ${ }^{45} \mathrm{Ca}$ in the labile pool of calcium across this surface. An increase in the turnover of calcium in this labile pool would accelerate the return of ${ }^{45} \mathrm{Ca}$ which entered bone during the two-day labeling period back to the circulation. Thus, the reduced bone ${ }^{45} \mathrm{Ca}$ content in gastrin-treated rats was likely to reflect enhanced bone turnover with ${ }^{45} \mathrm{Ca}$ being returned to the plasma compartment and eventually excreted. Our finding is consistent with a report that omeprazole-induced hypergastrinemia for 28 days stimulated transient uptake of ${ }^{45} \mathrm{Ca}$ into bone without increasing the bone ash weight, suggesting an increase in bone turnover without a net gain in bone mass (8). Together with the present data, it was likely that gastrin increased both the transient uptake of calcium into bone and the release of calcium from bone, i.e., accelerating bone turnover with no detectable long-term effect. The mechanism behind the gastrin-induced uptake of calcium by bone is not known at present, but it seemed likely that calcium was taken up into the labile bone fluid compartment rather than into the bone mineral compartment. However, the long-term effect may involve bone cells as the number of osteoclasts in some bones was increased after 8 weeks of omeprazole-induced hypergastrinaemia $(8)$.

In conclusion, we demonstrated that gastrin exerts a direct action on bone uptake of calcium. From the present study, we would like to propose that regarding calcium homeostasis, gastrin may have two beneficial effects. First, by shifting blood calcium to bone and muscle, gastrin helps to prevent postprandial hypercalcaemia in the event of high calcium intake. This is seen as an acute and transient effect of gastrin. This proposed action of gastrin may be of physiological significance since the circulating level of gastrin increased markedly during a meal (27, 28) and after an oral dose of calcium carbonate in humans (29). Second, by elevating the calcium level in the bone fluid compartment, gastrin could indirectly enhance bone mineralization and bone turnover under such circumstances as during growth in vitamin D-sufficient subjects or any condition where by bone matrix formation is normal but bone mineralization is impaired due to an insufficient supply of calcium. This long-term effect maybe of importance for bone remodelling especially during growth and development. However, the questions of whether gastrin is of physiological importance in calcium homeostasis and, if so, how it influences muscle and bone calcium handling remain to be answered.

The authors would like to thank Mrs. Wasana Saengumnart for technical assistance and Ms. Puckjira Gatebute for manuscript preparation. This study was supported in part by the Fund for the study of infectious diseases and host defence, Ramathibodi Hospital Foundation and Mahidol University Research Grant. 


\section{REFERENCES}

1) Schulak, J. A., and Kaplan, E. L. (1974): Gastrin-induced hypocalcemia in thyroparathyroidectomized rats. Metabolism, 23, 1103-1106.

2) Schulak, J. A., and Kaplan, E. L. (1975): The importance of the stomach in gastrin-induced hypocalcemia in the rat. Endocrinology, 96, 1217-1220.

3) Kaplan, E. L., North, P. T., Norberg, H. P., Schulak, J. A., and Hill, B. J. (1977): Evidence for role of the stomach in serum calcium regulation. J. Surg. Res., 22, 237241.

4) Krishnamra, N., and Limlomwongse, L. (1978): The influence of gastrin on plasma calcium, bile and gastric calcium secretion in the rat. Proc. Soc. Exp. Biol. Med., 158, 40-44.

5) Persson, P., Gagnemo-Persson, R., Orberg, J., Chen, D., and Hakanson, R. (1991): Effects of gastrin on calcium homeostasis in chickens. Endocrinology, 129, 1162-1166.

6) Persson, P., Hakanson, R., Axelson, J., and Sundler, F. (1989): Gastrin releases a blood calcium lowering peptide from the acid producing part of the rat stomach. Proc. Natl. Acad. Sci. U.S.A., 86, 2834-2838.

7) Hakanson, R., Axelson, J., and Persson, P. (1988): The role of stomach in the control of calcium homeostasis. Hepato-gastroenterol., 35, 38-39.

8) Hakanson, R., Persson, P., Axelson, J., Johnell, O., and Sundler, F. (1990): Evidence that gastrin enhances ${ }^{45} \mathrm{Ca}$ uptake into bone through release of a gastrin hormone. Regulatory Peptides, 28, 107-118.

9) Limlomwongse, L., and Krishnamra, N. (1981): The mechanism of action and target organ of gastrin-induced hypocalcemia. Proc. Soc. Exp. Biol. Med., 168, 72-76.

10) Mahoney, A. W., Holbrook, R. S., and Hendricks, D. G. (1975): Effects of calcium solubility on absorption by rats with induced achlorhydria. Nutr. Metab., 18, 310-317.

11) Recker, R. (1985): Calcium absorption and achlorhydria. N. Engl. J. Med., 313, 7073.

12) Eastell, R. (1985): Calcium absorption and achlorhydria. N. Engl. J. Med., 313, 1481-1482.

13) Klementschitsch, P., Kaplan, E. L., Heath III, H., North, P., and Lee, C.-H. (1979): A gastric factor, calcitonin, and the hypocalcemia induced by gastrointestinal hormones. Endocrinology, 105, 1243-1247.

14) Aou, S., Ma, J., Shiramine, K., and Hori, T. (1993): The stomach is the etiologic organ for immobilization-induced hypocalcemia in rats. Am. J. Physiol., 265, R1376R1379.

15) Persson, P., Gaagneomo-Persson, R., Chen, D., Axelson, J., Nylander, A. G., Johnell, O., and Hakanson, R. (1993): Gastrectomy causes bone loss in the rat: Is lack of gastric acid responsible? Scand. J. Gastroenterol, 28, 301-306.

16) Iry, A. C. (1940): The effects of gastrectomy in animals. Am. J. Dig. Dis., 7, 500-502.

17) Editorial (1986): Osteomalacia after gastrectomy. Lancet, 1, 77-78.

18) Eddy, R. L. (1971): Metabolic bone disease after gastrectomy. Am. J. Med., 50, 442449.

19) Klein, K. B., Orwoll, E. S., Lieberman, D.-A., Meier, D. E., McLung, M. R., and Parfitt, A. M. (1987): Metabolic bone disease in asymptomatic men after partial 
gastrectomy with Billroth II anastomosis. Gastroenterology, 92, 608-616.

20) Bisballe, S., Eriksen, E. F., Melsen, F., Mosekilde, L., Sorensen, O. H., and Hessor, I. (1991): Osteopenia and osteomalacia after gastrectomy: interrelations between biochemical markers of bone remodeling, vitamin $\mathrm{D}$ metabolites and bone histomorphometry. Gut, 32, 1303-1307.

21) Tovey, F. I., Hall, H. L., Ell, P. J., and Hobsley, M. (1991): Postgastrectomy osteoporosis. Br. J. Surg., 78, 1335-1337.

22) Fillipponi, P., Gregorio, F., Cristallini, S., Mannarelli, C., Blass, A., Scarponi, A. M., and Vespasiani, G. (1990): Partial gastrectomy and mineral metabolism: Effects on gastrin-calcitonin release. Bone Miner., 11, 199-208.

23) Resch, H., Pietschmann, S., Perneckeer, B., Krexner, E., and Willvonseder, R. (1992): The influence of partial gastrectomy on biochemical parameters of bone metabolism and bone density. Clin. Invest., 70(5), 426-429.

24) Parfitt, A. M. (1981): Integration of skeletal and mineral homeostasis, in Osteoporosis: Recent Advances in Pathogenesis and Treatment, ed. by DeLuca, H. G., Frost, H., Jee, W., Johnston, C., and Parfitt, A. M., University Park Press, Baltimore, pp. 115126.

25) Parfitt, A. M. (1987): Bone and plasma calcium homeostasis. Bone, 8 (suppl 1), S1S8.

26) Neuman, W. F., and Ramp, W. K. (1971): The concept of a bone membrane: Some implications, in Cellular Mechanisms for Calcium Transfer and Homeostasis, ed. by Nichols, G. Jr., and Wasserman, R. H., Academic Press, New York, pp. 197-206.

27) Lichtenberger, L. M., and Trier, J. S. (1979): Changes in gastrin levels, food intake and duodenal mucosal growth during lactation. Am. J. Physiol., 237, E98-E105.

28) Malmstrom, J., and Stadil, F. (1976): Gastrin content and gastrin release. Studies on the antral content of gastrin and its release to serum during stimulation by food. Scand. J. Gastroenterol., (suppl 37), 71-76.

29) Levant, J. A., Walsh, J. H., and Isenberg, J. I. (1973): Stimulation of gastric secretion and gastrin release by single oral doses of calcium carbonate in man. N. Engl. J. Med., 289, 555-558. 